\title{
Young Professionals' Conspicuous Consumption of Clothing
}

\author{
Abbie Lewis and Miguel Moital* \\ Department of Events and Leisure \\ Faculty of Management, Bournemouth University \\ United Kindgom \\ Emails: i7942311@bournemouth.ac.uk (A. Lewis) \\ mmoital@bournemouth.ac.uk (M. Moital)
}

\begin{abstract}
*Corresponding author. Address: Dorset House, Talbot Campus, Fern Barrow, BH12 5BB, United Kingdom; telephone +441202966674
\end{abstract}

Purpose: This paper examines the relationship between conspicuous consumption and public self-consciousness, materialism and domain-specific self-esteem, demographics and shopping behaviour.

Design/methodology/approach: Focusing on clothing, public self-consciousness, materialism and domain-specific self-esteem are examined in relation to two characteristics of clothing: expensive and fashionable. Using a sample of 261 UK young professionals, the paper compares the five factors across three levels of clothing conspicuous consumption (low, medium and high).

Findings: Findings indicate that while the five factors were associated to different levels of conspicuous consumption, the relationship was not always evident. Expensive clothing was more related to conspicuousness than fashionable clothing and differences between low and medium/high conspicuousness individuals appear to be larger than the difference between medium and high conspicuousness groups.

Practical implications: Price appears to be a more powerful influence on conspicuous consumption than the fashionable element and therefore a strategy focused on expensive prices is essential in attracting conspicuous consumers.

Originality/value: The study provides an insight into conspicuous consumption in the context of clothing and its relationship with public self-consciousness, materialism and self-esteem as they relate to the expensive and fashionable dimensions.

\section{CITE AS}

Lewis, A and Moital, M., 2016. Young Professionals' Conspicuous Consumption of Clothing, Journal of Fashion Marketing \& Management (forthcoming) 


\section{INTRODUCTION}

Economic factors such as increased disposable income have led to a steady growth in the sales of high end luxury goods (Truong 2010). In real terms, people's incomes are nearly three times higher than 1950, yet regardless of their salary bracket, $60 \%$ say they feel similarly deprived as they cannot afford to buy everything they really need (Mintel 2012). This could be partly due to people now regarding many high end goods as being essential. Status in today's society appears to be an important factor within social existence and personal comparison with others affects an individual's well-being (O'Cass and McEwen 2004). This can result in 'keeping up with the Joneses', an attempt to inflate the ego by portraying wealth and status with the acquisition and display of goods to impress others, typically known as conspicuous consumption (Veblen 1934). Conspicuous consumption is becoming more available to the masses resulting in people being increasingly judged through their material lifestyles (Varman and Vikas 2005).

The overall purpose of this paper is to examine the factors influencing conspicuous consumption in the context of clothing. Three factors are postulated to influence conspicuousness: public self-consciousness, the concern of appearance and impression (Tunnel 1984), materialism, the importance of acquiring material possessions (Richins and Dawson 1992) and self-esteem, judging themselves by worthiness (Rosenberg 1965). As clearly both the aesthetic and price elements are vitally important to remain competitive in the industry, these influences are examined in relation to the expensive and fashionable characteristics of clothing. By analysing perceptions across these two dimensions, the research examines whether conspicuous purchasing perceptions change depending on the feature of the product. In addition, the relationship between conspicuousness and demographic characteristics and clothing shopping behaviour are also examined. Analysis of these will 
support marketers in understanding consumers' clothing motivations and purchasing behaviours in order to promote marketing strategies to increase sales for specific markets.

As a highly visible product, clothing was chosen to study consumers' usage as garments express personality and values (Phau and Cheong 2009). The UK clothing market remained relatively robust throughout the recession, growing $13 \%$ from 2007-2012 to an annual $£ 51$ billion turnover benefiting from the constant demand of a quick turnover of new fashion trends (Mintel 2013a). The UK's luxury and expensive market is expected to double since 2012 to $£ 12.2$ billion in 2017 (Walpole 2013). The clothing industry’s extremely competitive nature and high profitability continues to be of interest to marketing practitioners and researchers (Carpenter et al. 2005).

\section{LITERATURE REVIEW}

\subsection{Conspicuous Consumption}

Conspicuous consumption describes the possession and display of expensive items to suggest affluence, attract attention to one's wealth and inflate the ego (Veblen, 1934). Conspicuous goods are consumed due to their ability to satisfy social needs as well as material needs, differing from other frequently purchased goods (Belk 1988; Grubb and Grathwohl 1967) by being prone to visual display or overt usage in the presence of others (O'Cass and McEwen 2004). Duesenberry (1949) modernised Veblen's work and proposed that social comparison is the forefront for consumption decisions, known as the bandwagon effect. In other words, people purchase goods according to their perception of what is usual for their reference group and often product satisfaction results from audience reaction (Wong, 1997). There is evidence that conspicuous consumption is related to the snob effect, which postulates that consumers purchase expensive goods not possessed by the common populace (Mason, 1981; Kastanakis 
and Balabanis, 2014). Veblen, Duesenberry and Mason, as well as the more recent work (e.g. Kastanakis and Balabanis, 2014), show how conspicuous consumption has changed from an exclusive behaviour to mass consumption with the elitists fighting to keep it exclusive (Page 1992).

According to Trigg (2001), conspicuous consumption has become more sophisticated and subtle due to its multiple symbolic meanings. Studies show that to specific groups, conspicuous consumption means the ostentation of wealth with symbolic items to gain recognition or status (Chen et al. 2008; Kastanakis and Balabanis, 2014), high self-concept (Sirgy 1982, Kastanakis and Balabanis, 2014) and uniqueness (Tepper-Tian et al. 2001). However, according to Chaudhuri and Majumdar (2006) those with superior taste but less money can now aim to compete with those with money but no taste in order to join a social group. Therefore, in addition to the significance of monetary value (the expensive dimension), fashion is becoming a major attribute to conspicuousness (the fashionability dimension). Fashionability is related to product design and style and fulfils an aesthetic role rather than a functional one (Rahman, Jiang and Liu, 2010). Recent research further supports the dual perspective on conspicuous consumption. Woodside (2012) found that both design and price could act as conspicuous symbols, while Kapferer and Michaut (2015) concluded that luxury, which is common attribute of conspicuous products, can be signalled by both the hedonic/beauty as well as price element.

As noted earlier, conspicuous consumption is influenced by many different factors. This study examines the influence public self-consciousness, materialism and self-esteem have on conspicuous consumption in clothing. Each of these influences is now reviewed. 


\subsection{Public Self-Consciousness and Conspicuous Consumption}

Public self-consciousness is "the degree to which persons recognise and are concerned about the way they are perceived by others" (Fenigstein 1979, p.77). There is evidence that those high in public self-consciousness are more concerned about the self as a social object (Xu 2008) and consequently they try to create a favourable public image (Fenigstein 1979), use self-presentation strategies to gain approval (Doherty and Schlenker 1991) by consuming goods to create the desired impressions (Burnkrant and Page 1981), preferring expensive brands to bargain brands (Bushman 1993; Tolbert, Kohli and Suri, 2014). Previous research has found public self-consciousness to be related to conspicuous consumption (e.g. Gould and Barak, 2001; Ghosh and Varshney, 2013). Goods in public view can be regarded as conspicuous (Bearden and Etzel 1982) with research suggesting that conspicuous consumption significantly shapes preferences for publicly consumed products (Vigneron and Johnson 2004) in order to reach social status and representation (Wiedmann et al. 2007). In the context of fashion, research shows that fashionable clothing can be used to negotiate a consumer's public images, manage appearance and balance their sense of affiliation and autonomy (Banister and Hogg 2004). Based on the above, it is suggested that public self-consciousness and conspicuous consumption will be related. Therefore it is hypothesised that:

Hypothesis 1: High levels of public self-consciousness in the context of clothing are related to higher levels of conspicuous consumption.

a) High levels of public self-consciousness in the context of expensive clothing are related to higher levels of conspicuous consumption.

b) High levels of public self-consciousness in the context of fashionable clothing are related to higher levels of conspicuous consumption. 


\subsection{Materialism and Conspicuous Consumption}

Belk (1985) defined materialism as a consumer's attachment to worldly possessions while Richins and Dawson (1992) defined it as the importance of acquiring and owning material goods to achieve major life goals or desired states. There is evidence that materialists place possessions at the centre of life to gauge personal and others' success and happiness (Podoshen and Andrzejewski 2012) by the quantity and quality of possessions (Richins and Dawson 1992). The overall portrait of materialists shows they are responsive to externals, self-centred and less satisfied with life (Tatzel 2002; Winkelmann, 2012). In order to satisfy materialist needs, high materialistic consumers use people from a higher socioeconomic status as referents, incurring high motivation for potentially owning overly expensive goods as suggested by Dittmar (2005). Furthermore, they believe acquisition is important for success and that high levels of consumption lead to increased satisfaction (Dittmar 2005). It has also been suggested that high materialist consumers are driven to consume more status goods (Mason 1981) in public places (O’Cass and Muller 1999; Richins and Dawson 1992), enjoying the fashionable and technological prowess of their possessions that they believe facilitates admiration from others (Tatzel 2002). Therefore, materialism and conspicuous consumption are often associated as shown in two studies where materialism was the main driver of Brazilian teens' attitudes toward luxury brands (Gil et al. 2012) and materialistic Americans were more likely to purchase conspicuous goods (Pyone and Isen 2011). Therefore, a second hypothesis is formulated:

Hypothesis 2: High levels of materialism in the context of clothing is related to higher levels of conspicuous consumption.

a) High levels of materialism in the context of expensive clothing are related to higher levels of conspicuous consumption.

b) High levels of materialism in the context of fashionable clothing are related to higher levels of conspicuous consumption. 


\subsection{Self-esteem and Conspicuous Consumption}

James (1890) is credited with the initial writing on self-esteem and defined it in terms of a balance between reality-based attainments relative to an individual's goals or aspirations. Thus, high self-esteem results from a close match between aspirations (ideal self) and current self-image. In the turn of the millennium, Wadman (2000) pointed out that society had converted the drive for self-esteem into a drive to possess high quality goods and therefore an individual whose annual consumption remained static suffered progressively poorer selfesteem as their peers upgraded the quality of their consumption goods (Wadman 2000). To avoid this loss of self-esteem, individuals will try to 'keep up with the Joneses' by increasing their consumption expenditure, known as the demonstration effect (Duesenberry 1949). There is strong evidence that self-esteem is related to conspicuousness. Truong and McColl (2011) identified a strong relationship between self-esteem and the consumption of luxury goods, while Sivanathan and Pettit (2010) found that those with low self-esteem relied on the use of conspicuous products in an attempt to alter their status. Domain-specific self-esteem refers to one particular self-image in a particular area (Rubin 1998) and is most often used to explain an individual's behaviour (Rosenberg et al. 1995). Consequently, domain-specific selfesteem's predictive ability for outcomes is measured at a specific level (Marsh et al. 2006), in this study in relation to the consumption of clothing.

Hypothesis 3: Low level of domain-specific self-esteem in the context of clothing is related to higher levels of conspicuous consumption.

a) Low level of domain-specific self-esteem in the context of expensive clothing is related to higher levels of conspicuous consumption.

b) Low level of domain-specific self-esteem in the context of fashionable clothing is related to higher levels of conspicuous consumption. 


\subsection{Demographics, Shopping Behaviour and Conspicuous Consumption}

The literature shows that certain demographic groups are more prone to engage in conspicuous consumption. For example, Spero and Stone (2004) found that middle-aged consumers spend more on larger conspicuous products while younger consumers spend more on smaller conspicuous products such as clothing, and another study found men to be more conspicuous than women (Sundie et al. 2011). In addition, studies show that conspicuous continues to be more significant in affluent societies (Hirsch 1976; Podoshen et al, 2011), where higher educated and wealthier individuals have stronger conspicuous signalling needs (Amaldoss and Jain 2005). However, some authors (e.g. Heffetz, 2011) ague that demographics are irrelevant. Existing research also shows that shopping behaviour is related to conspicuous consumption. For example, highly conspicuous individuals are more likely to get into debt (Scott and Lewis 2001) and to rationalise a purchase (O'Shaughnessy and O'Shaughnessy 2002). However, some inconsistencies in results have been found. For example, Corneo and Jeanne (1997) found that snobbish individuals are unlikely to purchase conspicuous sale items, while Amaldoss and Jain (2005) disagree stating that the snobbish will procure sale items when other individuals are involved. Given the uncertainty about how they are related, this paper also examines the relationship between demographic and shopping behaviour and conspicuous consumption.

\section{METHODOLOGY}

The literature provided key insights into the concept of conspicuous consumption and its transformation from being solely luxurious goods purely for the high class to the inclusion of more affordable products for the masses. The review has allowed an understanding of the characteristics of public self-consciousness, materialistic individuals and how levels of self- 
esteem affect their relationship with conspicuous consumption. Previous research on these influences has treated them as generic influences, devoid of context (see, for example, $\mathrm{Xu}$ (2008) for self-consciousness and Podoshen, Li and Zhang (2011) for materialism). In attempting to examine the relationship between conspicuous consumption and these variables in the context of expensive and fashionable clothing, as well as how conspicuous consumption varies across both personal characteristics and consumption patterns, the research takes a quantitative approach.

\subsection{Questionnaire Design}

Measurement scales were used to understand consumers' level of conspicuous consumption, public self-consciousness, materialism and self-esteem. In addition, specific questions were asked regarding attitudes and reasons for purchasing clothing followed by demographic and shopping behaviour questions. Questions referred to expensive clothing and to fashionable clothing separately as they constitute two main market areas of the clothing sector and also by definition they can be identified as conspicuous products (Nelissen and Marijn 2011). Existing scales were employed to measure each of the concepts. The wording was slightly adapted for all scales to focus on clothing. A 5-point Likert scale, ranging from strongly disagree to strongly agree, was chosen.

Moschis (1981, p.124) scale was used to measure conspicuous consumption because it shows the "cognitive orientation concerning the importance of conspicuous consumption and selfexpression via conspicuous consumption". Fenigsteign et al. (1975)'s 7-item scale of public self-consciousness shows high reliability as well as good fit to the purpose of this study and therefore was employed. As some items were deemed irrelevant to clothing, the four that best reflected the purchase of clothing were selected. Richins and Dawson's (1992) scale assesses an individual's level of materialism with three components; possession defined success, 
acquisition centrality and acquisition as the pursuit of happiness. Only 'possession defined success' was included in the study as the other two were difficult to apply to the specific content of clothing given that they focused more on the general state of happiness and wellbeing. Finally, to analyse domain-specific self-esteem, a 5-item scale containing selfesteem questions in the context of clothing was adapted from Marsh et al. (2006). A pilot questionnaire was sent to 10 respondents asking for feedback on completion time, layout, clarity of instructions, question wording and answer category wording. Minor changes were made to the wording of some questions, definitions added and subjective words explained.

\subsection{Sampling}

The sample chosen were young professionals, defined as 18-35 years with a degree or professional qualifications working in administrative, managerial or professional areas. As purchasing habits change throughout an individual's life cycle (Spero and Stone 2004), focusing on a specific sample allows for greater consistency when analysing and comparing data. Non-probability, convenience and snowballing sampling methods used. A link to the online questionnaire was distributed through emails and social media to the researchers' contacts, and respondents were also asked to forward on the questionnaire to others that met the sampling criteria. Stoker (1989) argues that the sample size for non-parametric tests is usually determined by the smallest group, usually 50-100 respondents. Given that the independent variable in this research has three sub-groups, assuming the middle value of 75 per subgroup the minimum respondents required should be 225 . A total of 261 valid questionnaires were used for analysis. 


\subsection{Profile of Sample}

The analysis of the demographic characteristics of respondents is presented in Table 1. There were slightly more males $(54.8 \%)$ than females $(45.2 \%)$, with a good spread of respondents across age and marital status. The majority had no dependent children. Four out of 10 made mortgage payments $(41.4 \%)$, over a third rented $(36.8 \%)$, some lived with family $(18.8 \%)$, with the smallest sample owning a house outright (3.1\%). These demographics reflect a lifestyle of a young professional being more likely a first time buyer and just starting a family. The highest personal income bracket percentage was £20,000-£34,999 (42.1\%) and household income $£ 50,000+(39.1 \%)$ closely followed by $£ 35,000-£ 49,999(37.5 \%)$, suggesting that a proportion of respondents have at least two household incomes.

Table 1: Demographic profile of respondents $(n=261)$

\begin{tabular}{|l|c|l|c|}
\hline & $\%$ & & $\%$ \\
\hline Gender & & Housing Situation & \\
\hline Male & 54.8 & Rental & 36.8 \\
\hline Female & 45.2 & Living with family & 18.8 \\
\hline Age & & Owner paying mortgage & 41.4 \\
\hline $19-24$ & 23.8 & Owner no mortgage & 3.1 \\
\hline $25-29$ & 37.5 & Personal income bracket & \\
\hline $30-35$ & 38.7 & Up to £19,999 & 18 \\
\hline Marital Status & & $£ 20,000-£ 34,999$ & 42.1 \\
\hline Single & 39.1 & $£ 35,000-£ 49,999$ & 25.3 \\
\hline $\begin{array}{l}\text { Living with } \\
\text { partner }\end{array}$ & 30.3 & $£ 50,000+$ & 14.6 \\
\hline Married & 30.7 & Household income bracket & \\
\hline $\begin{array}{l}\text { Dependent } \\
\text { Children }\end{array}$ & & Up to £19,999 & 3.1 \\
\hline None & 54.8 & $£ 20,000-£ 34,999$ & 20.3 \\
\hline $1-2$ & 32.6 & $£ 35,000-£ 49,999$ & 37.5 \\
\hline $3-4$ & 12.6 & $£ 50,000+$ & 39.1 \\
\hline
\end{tabular}




\subsection{Data Analysis}

Initially, respondents were ranked by their mean for conspicuous consumption of clothing responses and divided into three even groups of 87 ; low, medium and high levels of conspicuousness. Shapiro-Wilk's test for assessing normality showed that many variables were not normally distributed. Therefore, the non-parametric tests Kruskal-Wallis and the Spearman Rank correlation were run, as they do not assume normality of distribution or homogeneity of variance (Gray and Kinnear 2012). Kruskal-Wallis test was run with conspicuous consumption being the independent variable and public self-consciousness, materialism, self-esteem, demographic variables (measured at the ordinal level) and shopping behaviour as the dependent variables. When there was a statistical difference, a pairwise comparisons test was utilised using Dunn's (1964) procedure, with a Bonferroni correction for multiple comparisons using the adjusted significance $(0.05 / 3=0.167)$.

Kruskal-Wallis test is better interpreted when medians are looked at, however due to the small Likert scale, the mean value is shown as it makes it easier to interpret the results. Chi-square was employed to examine the relationship between conspicuousness and demographic variables measured at the categorical level. Spearman Rank correlation was employed to examine the strengths of the linear relationship (Weinberg and Abramowitz 2002) between conspicuous consumption and public self-consciousness, materialism and self-esteem. A coefficient value between $0.1<\mathrm{r}<0.3$ is a small correlation, $0.3<\mathrm{r}<0.5$ is a medium correlation and $r>0.5$ is a large correlation (Cohen 1988). 


\section{RESULTS}

\subsection{Public Self-Consciousness and Conspicuous Consumption}

As shown in Table 2, Kruskal-Wallis results indicate statistically significant differences between an individual's conspicuous clothing purchases and their public self-consciousness $(p<0.001)$. Pairwise comparisons confirm that the higher the public self-consciousness in the context of expensive and fashionable clothing, the higher the levels of conspicuousness. This relationship is evident for all variables showing differences between low, medium and high conspicuous individuals. These finding are consistent with previous research which found a positive relationship between conspicuous consumption and public self-consciousness (Gould and Barak 2001; Tunnel 1984). Hypotheses 1a and 1b are supported, and therefore hypothesis 1 is also supported.

The means show that low, medium and high conspicuous individuals place more importance on fashionable clothing with all fashionable variables having a higher mean than their equivalent expensive variables (Table 2). This could be due to fashionable clothing being more visible than expensive clothing; it is worn then discarded when the next fashion trend appears (Scott, 2010). All correlations show a strong positive relationship with conspicuous consumption as values are above 0.5 (Cohen 1988). The strongest correlations refer to the need for others to be aware that their clothing is expensive (0.742) or fashionable (0.727). All variables when ranked show that expensive and fashionable alternate throughout showing little difference for the type of clothing. The strong correlation further support hypotheses $1,1 \mathrm{a}$ and $1 b$. 
Table 2 - Mean, Kruskal-Wallis and Correlations for Public Self-Consciousness, Materialism and Domain-Specific Self-Esteem

\begin{tabular}{|c|c|c|c|c|c|c|}
\hline \multirow[t]{2}{*}{ Statement } & \multicolumn{3}{|c|}{ Mean } & \multirow{2}{*}{$\begin{array}{c}\text { Kruskal } \\
\text { Wallis } \\
\text { (p-value) }\end{array}$} & \multicolumn{2}{|c|}{ Correlation } \\
\hline & $\begin{array}{c}\text { Low } \\
\text { CC }\end{array}$ & $\begin{array}{l}\text { Medium } \\
\text { CC }\end{array}$ & $\underset{\text { CC }}{\text { High }}$ & & R-value & Sig. \\
\hline \multicolumn{7}{|c|}{ Public Self-Consciousness } \\
\hline \multicolumn{7}{|c|}{ Expensive clothing } \\
\hline $\begin{array}{l}\text { Wearing expensive clothing will improve my } \\
\text { appearance. }\end{array}$ & $2.46^{\mathrm{mh}}$ & $3.74^{\text {th }}$ & $4.29^{\mathrm{lm}}$ & $<0.001$ & 0.742 & $<0.001$ \\
\hline $\begin{array}{l}\text { Expensive clothes I wear should present an image of } \\
\text { wealth. }\end{array}$ & $2.24^{\mathrm{mh}}$ & $3.33^{\text {th }}$ & $3.95^{\mathrm{Im}}$ & $<0.001$ & 0.727 & $<0.001$ \\
\hline Others should be aware that I wear expensive clothing. & $1.93^{\mathrm{mh}}$ & $3.52^{\mathrm{lh}}$ & $4.11^{\mathrm{lm}}$ & $<0.001$ & 0.715 & $<0.001$ \\
\hline Expensive clothes I wear make a good impression. & $2.65^{\mathrm{mh}}$ & $3.89^{\text {lh }}$ & $4.38^{\mathrm{lm}}$ & $<0.001$ & 0.699 & $<0.001$ \\
\hline \multicolumn{7}{|c|}{ Fashionable clothing } \\
\hline $\begin{array}{l}\text { Wearing fashionable clothing will improve my } \\
\text { appearance. }\end{array}$ & $2.82^{\mathrm{mh}}$ & $4.10^{\mathrm{lh}}$ & $4.39^{\mathrm{lm}}$ & $<0.001$ & 0.698 & $<0.001$ \\
\hline $\begin{array}{l}\text { The fashionable clothes I wear should present an } \\
\text { image of wealth. }\end{array}$ & $2.80^{\mathrm{mh}}$ & $4.04^{\mathrm{lh}}$ & $4.58^{\mathrm{lm}}$ & $<0.001$ & 0.652 & $<0.001$ \\
\hline $\begin{array}{l}\text { Others should think that the clothes I wear are } \\
\text { fashionable. }\end{array}$ & $2.57^{\mathrm{mh}}$ & $3.96^{\mathrm{lh}}$ & $4.34^{\mathrm{lm}}$ & $<0.001$ & 0.640 & $<0.001$ \\
\hline $\begin{array}{l}\text { I'm concerned that the fashionable clothes I wear } \\
\text { make a good impression. }\end{array}$ & $3.11^{\mathrm{mh}}$ & $4.14^{\mathrm{lh}}$ & $4.44^{\mathrm{lm}}$ & $<0.001$ & 0.593 & $<0.001$ \\
\hline \multicolumn{7}{|c|}{ Materialism } \\
\hline \multicolumn{7}{|c|}{ Expensive clothing } \\
\hline $\begin{array}{l}\text { The expensive clothes I own say a lot about how } \\
\text { successful I am in life. }\end{array}$ & $2.25^{\mathrm{mh}}$ & $3.31^{\mathrm{lh}}$ & $3.83^{\mathrm{lm}}$ & $<0.001$ & 0.741 & $<0.001$ \\
\hline I like to own expensive clothes to impress people. & $1.91^{\mathrm{mh}}$ & $3.66^{\mathrm{lh}}$ & $4.20^{\mathrm{lm}}$ & $<0.001$ & 0.727 & $<0.001$ \\
\hline I admire people who own expensive clothes & $2.12^{\mathrm{mh}}$ & $3.46^{\mathrm{lh}}$ & $4.09^{\mathrm{lm}}$ & $<0.001$ & 0.692 & $<0.001$ \\
\hline $\begin{array}{l}\text { I don't pay much attention to whether other people } \\
\text { own expensive clothes (R). }\end{array}$ & $2.12^{\mathrm{mh}}$ & $3.52^{\mathrm{lh}}$ & $4.16^{\mathrm{lm}}$ & $<0.001$ & 0.680 & $<0.001$ \\
\hline $\begin{array}{l}\text { I don't regard the amount of expensive clothing a } \\
\text { person owns as a sign of success (R). }\end{array}$ & $2.05^{\mathrm{mh}}$ & $3.24^{\mathrm{lh}}$ & $3.83^{\mathrm{lm}}$ & $<0.001$ & 0.672 & $<0.001$ \\
\hline \multicolumn{7}{|c|}{ Fashionable clothing } \\
\hline $\begin{array}{l}\text { The fashionable clothes I own say a lot about how } \\
\text { successful I am in life. }\end{array}$ & $2.40^{\mathrm{mh}}$ & $3.58^{1}$ & $3.91^{1}$ & $<0.001$ & 0.671 & $<0.001$ \\
\hline I like to own fashionable clothes to impress people. & $2.23^{\mathrm{mh}}$ & $3.80^{1}$ & $4.15^{1}$ & $<0.001$ & 0.669 & $<0.001$ \\
\hline I admire people who own fashionable clothing. & $2.33^{\mathrm{mh}}$ & $3.70^{1}$ & $3.90^{1}$ & $<0.001$ & 0.595 & $<0.001$ \\
\hline $\begin{array}{l}\text { I don't pay much attention to whether other people } \\
\text { own fashionable clothes (R). }\end{array}$ & $2.11^{\mathrm{mh}}$ & $3.25^{\mathrm{lh}}$ & $3.96^{\mathrm{lm}}$ & $<0.001$ & 0.583 & $<0.001$ \\
\hline $\begin{array}{l}\text { I don't regard the amount of fashionable clothing a } \\
\text { person owns as a sign of success (R). }\end{array}$ & $2.30^{\mathrm{mh}}$ & $2.79^{1}$ & $2.97^{1}$ & $<0.001$ & 0.334 & $<0.001$ \\
\hline \multicolumn{7}{|l|}{ 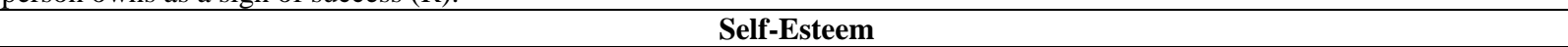 } \\
\hline \multicolumn{7}{|c|}{ Expensive clothing } \\
\hline Wearing expensive clothing increased my self-esteem. & $2.69^{\mathrm{mh}}$ & $3.93^{\text {lh }}$ & $4.33^{\operatorname{lm}}$ & $<0.001$ & 0.737 & $<0.001$ \\
\hline $\begin{array}{l}\text { When wearing expensive clothes I feel that I am a } \\
\text { person of worth who is the equal of others. }\end{array}$ & $2.56^{\mathrm{mh}}$ & $3.74^{\mathrm{lh}}$ & $4.32^{\mathrm{lm}}$ & $<0.001$ & 0.697 & $<0.001$ \\
\hline I often buy expensive clothes to boost my self-esteem. & $2.14^{\mathrm{mh}}$ & $3.27^{\mathrm{lh}}$ & $3.98^{\mathrm{lm}}$ & $<0.001$ & 0.678 & $<0.001$ \\
\hline $\begin{array}{l}\text { Wearing expensive clothes helps me feel I am leading } \\
\text { a successful life. }\end{array}$ & $2.29^{\mathrm{mh}}$ & $3.62^{\mathrm{lh}}$ & $4.27^{\mathrm{lm}}$ & $<0.001$ & 0.659 & $<0.001$ \\
\hline $\begin{array}{l}\text { I feel good about myself when wearing expensive } \\
\text { clothes. }\end{array}$ & $3.08^{\mathrm{mh}}$ & $4.06^{\mathrm{lh}}$ & $4.51^{\mathrm{lm}}$ & $<0.001$ & 0.643 & $<0.001$ \\
\hline \multicolumn{7}{|c|}{ Fashionable clothing } \\
\hline $\begin{array}{l}\text { Wearing fashionable clothing increases my self- } \\
\text { esteem. }\end{array}$ & $2.69^{\mathrm{mh}}$ & $4.09^{1}$ & $4.31^{1}$ & $<0.001$ & 0.641 & $<0.001$ \\
\hline $\begin{array}{l}\text { When wearing fashionable clothes I feel that I am a } \\
\text { person of worth who is the equal of others. }\end{array}$ & $2.65^{\mathrm{mh}}$ & $3.87^{1}$ & $4.09^{1}$ & $<0.001$ & 0.627 & $<0.001$ \\
\hline $\begin{array}{l}\text { I often buy fashionable clothes to boost my self- } \\
\text { esteem. }\end{array}$ & $2.51^{\mathrm{mh}}$ & $3.60^{\mathrm{lh}}$ & $4.05^{\mathrm{lm}}$ & $<0.001$ & 0.581 & $<0.001$ \\
\hline $\begin{array}{l}\text { Wearing fashionable clothes helps me feel I am } \\
\text { leading a successful life. }\end{array}$ & $2.19^{\mathrm{mh}}$ & $3.65^{1}$ & $4.08^{1}$ & $<0.001$ & 0.581 & $<0.001$ \\
\hline $\begin{array}{l}\text { I feel good about myself when wearing fashionable } \\
\text { clothes. }\end{array}$ & $3.11^{\mathrm{mh}}$ & $4.11^{1}$ & $4.30^{1}$ & $<0.001$ & 0.539 & $<0.001$ \\
\hline
\end{tabular}

Legend: CC - Conspicuous Consumption; ns - non-significant; 1 - indicates statistical difference with low CC at the 0.05 level; $\mathrm{m}$ - indicates statistical difference with medium $\mathrm{CC}$ at the 0.05 level; $\mathrm{h}$ - indicates statistical difference with high $\mathrm{CC}$ at the 0.05 level. 


\subsection{Materialism and Conspicuous Consumption}

The analysis show statistically significant differences between materialism regarding clothing and conspicuous consumption (Table 2), supporting previous studies (Richins 1994; Mason 1981). All of the expensive variables have a significant pairwise comparison showing that higher conspicuous individuals higher materialism regarding expensive clothing; hypothesis $2 \mathrm{a}$ is supported. Hypothesis $2 \mathrm{~b}$ is only partially supported by showing a significant difference between low and medium and between low and high conspicuous individuals, but no difference between medium and high. Therefore, hypothesis 2 is partially supported. The mean values show that highly conspicuous individuals appear to place more emphasis on expensive clothing to show success, consistent with the view of Richins and Dawson (1992). The expensive variables show a much larger difference between the low and medium groups when compared to medium and high. Therefore, low conspicuous individuals appear to have a greater difference of opinion compared to the other two.

All correlations demonstrate a strong association apart from 'I don't regard the amount of fashionable clothing a person owns as a sign of success $(\mathrm{R})^{\prime}$ ( $\left.\mathrm{r}=0.334\right)$ showing a medium correlation. The highest correlated variables are about liking to own expensive ( $r=0.741)$ and fashionable ( $\mathrm{r}=0.727$ ) clothes to impress people, followed by not paying much attention to whether other people own fashionable $(r=0.692)$ or expensive $(r=0.680)$ clothes $(R)$ '. This shows that making an impression and what others wear, regardless whether expensive or fashionable, are strongly associated to conspicuousness. However, the remainder of the variables did show a stronger correlation for expensive clothing when compared to fashionable. The variables stating 'expensive/fashionable clothes I own say a lot about how successful I am in life' and 'I don't regard the amount of expensive/fashionable clothing a 
person owns as a sign of success' both have much higher correlations for expensive $((=0.669$, $\mathrm{r}=0.671)$ than fashionable $(\mathrm{r}=0.583, \mathrm{r}=0.334)$. Therefore, individuals demonstrate success by placing more emphasis on expensive, consistent with Richins and Dawson (1992) and supporting the earlier findings from the mean tests.

\subsection{Self-esteem and Conspicuous Consumption}

The results (Table 2) indicate that the relationship between domain-specific self-esteem in the context of clothing and conspicuous consumption is statistically significant. There was a significant difference between low and medium and between low and high conspicuous individuals using clothing to boost their self-esteem. However, while the medium and high conspicuousness groups differ in all the expensive clothing variables, four variables related to fashionable clothing show no difference between medium and high conspicuous individuals. Therefore, Hypothesis $3 \mathrm{a}$ was accepted but Hypothesis $3 \mathrm{~b}$ was only partially accepted. As a consequence, Hypothesis 3 is only partially supported.

The mean tests (Table 2) show that there is a greater difference between low and medium conspicuous individuals compared to medium and high indicating a much greater difference in opinion for low conspicuous individuals compared to medium and high. The correlation results indicate that the strongest relationship to conspicuous consumption is for the variable 'wearing expensive clothes helps me feel I am leading a successful life', with the third highest variable being its fashion equivalent. Therefore, an individual's self-esteem regarding clothing and success in life is highly correlated with conspicuous consumption. Generally speaking, the stronger the correlation to conspicuous consumption, the more likely that the variable involved expensive clothing to boost self-esteem. 


\subsection{Demographics, Shopping Behaviour and Conspicuous Consumption}

With the exception of gender and household income, demographics are related to conspicuous consumption of clothing (Table 3). There is a difference between low and medium conspicuous individuals except for personal income. Only personal income shows a difference between medium and high conspicuous consumption groups. A low conspicuous individual is most likely to be aged between $30-35$ years old (53.9\%), married (51.7\%) and have 1-2 children (40.4\%). However, with $25.8 \%$ having 3-4 children, this is much higher than medium or high conspicuous individuals. They are more likely to be an owner paying a mortgage (56.2\%) and have a personal income of $£ 20,000-£ 49,999$. Medium conspicuous individuals are most likely $24-29$ years old (54.7\%), single (38.4\%) or in a stable relationship (43.0\%) and have no children (61.6\%). They are most likely living in rental accommodation (45.3\%) with a personal income of $£ 20,000-£ 34,999$ (48.8\%). High conspicuous individuals are most likely $24-29$ years old $(46.5 \%)$ or $30-35(37.2 \%)$, with no children $(69.8 \%)$. They most likely live in rental accommodation $(40.7 \%)$ or own a house with a mortgage $(36.0 \%)$ and earn $£ 20,000$ $£ 34.999(40.7 \%)$.

The Kruskal-Wallis test shows that there is a significant difference between all the 6 shopping behaviour variables and level of conspicuousness (Table 4). All groups differ in their shopping behaviour with the exception of regretting their expenditure and previous debts incurred on clothing, where no differences were found between medium and high conspicuous consumption. A low conspicuous individual is most likely to purchase expensive clothes every six months (41.6\%) and fashionable clothes monthly $(29.2 \%)$ or six monthly $(28.1 \%)$, spending either less than $£ 50(38.2 \%)$ or $£ 51-£ 100$ (31.5\%) on clothing. The vast majority will never go into debt when purchasing clothes $(84.3 \%)$ and never regret the amount they spend (49.4\%). They will often (33.7\%) or always (32.6\%) let others know if an expensive item was purchased at a discount and will always do so (41.6\%) for fashionable items. 
Table 3 - Frequencies and Statistical differences across demographic variables

\begin{tabular}{|c|c|c|c|c|}
\hline \multirow[t]{2}{*}{ Statement } & \multicolumn{3}{|c|}{$\%$} & \multirow[b]{2}{*}{ (p-value) } \\
\hline & $\begin{array}{c}\text { Low } \\
\text { CC }\end{array}$ & $\begin{array}{c}\text { Medium } \\
\text { CC }\end{array}$ & $\begin{array}{c}\text { High } \\
\text { CC }\end{array}$ & \\
\hline \multicolumn{5}{|c|}{ Socio-demographic characteristics } \\
\hline Gender * & & & & ns \\
\hline Male & 56.2 & 46.5 & 61.6 & \\
\hline Female & 43.8 & 53.5 & 38.4 & \\
\hline$\overline{\text { Age } * *}$ & $\mathbf{m}$ & $\mathbf{L}$ & & $<0.05$ \\
\hline $18-23$ & 21.3 & 20.9 & 16.3 & \\
\hline $24-29$ & 24.7 & 54.7 & 46.5 & \\
\hline $30-35$ & 53.9 & 24.4 & 37.2 & \\
\hline Marital Status * & $\mathbf{m h}$ & $\mathbf{L}$ & l & $<0.001$ \\
\hline Single & 27.0 & 38.4 & 52.3 & \\
\hline Living with partner & 21.3 & 43.0 & 26.7 & \\
\hline Married & 51.7 & 18.6 & 20.9 & \\
\hline Dependent children $* *$ & $\mathbf{m h}$ & $\mathbf{L}$ & 1 & $<0.001$ \\
\hline None & 33.7 & 61.6 & 69.8 & \\
\hline $1-2$ & 40.4 & 29.1 & 27.9 & \\
\hline $3-4$ & 25.8 & 9.3 & 2.3 & \\
\hline Housing situation * & $\mathbf{m h}$ & $\mathbf{L}$ & l & $<0.01$ \\
\hline Rental & 24.7 & 45.3 & 40.7 & \\
\hline Living with family & 14.6 & 23.3 & 18.6 & \\
\hline Owner paying mortgage & 56.2 & 31.4 & 36.0 & \\
\hline Owner no mortgage & 4.5 & 0 & 4.7 & \\
\hline Personal income $* *$ & $\mathbf{M}$ & Lh & $\mathbf{m}$ & $<0.05$ \\
\hline Up to $£ 19,999$ & 12.4 & 30.2 & 11.6 & \\
\hline$£ 20,000-£ 34,999$ & 37.1 & 48.8 & 40.7 & \\
\hline$£ 35,000-£ 49,999$ & 36.0 & 12.8 & 26.7 & \\
\hline$£ 50,000+$ & 14.6 & 8.1 & 20.9 & \\
\hline Household income ** & & & & ns \\
\hline Up to $£ 19,999$ & 3.4 & 4.7 & 1.2 & \\
\hline$£ 20,000-£ 34,999$ & 15.7 & 24.4 & 20.9 & \\
\hline$£ 35,000-£ 49,999$ & 29.2 & 39.5 & 44.2 & \\
\hline$£ 50,000+$ & 51.7 & 31.4 & 33.7 & \\
\hline
\end{tabular}

Medium level of conspicuous individuals are most likely to purchase expensive clothing every six months (50.0\%) and fashionable clothing monthly (75.6\%). They spend from $£ 101-£ 300$ per month on clothing and never go into debt (37.2\%) followed by rarely $(26.7 \%)$. They rarely $(32.6 \%)$ or sometimes $(32.6 \%)$ regret the amount they have spent. They will often let others be aware if their expensive (36.0\%) or fashionable (41.9\%) clothing was bought at discount. High conspicuous individuals are most likely to purchase expensive clothing monthly (38.4\%) and fashionable clothing either monthly (48.8\%) or weekly (43.0\%). They are most likely to 
spend $£ 101-£ 200$ on clothing (25.6\%) followed by $£ 301-£ 500(20.9 \%)$ and never $(36.0 \%)$ or rarely $(30.2 \%)$ go into debt. Many will sometimes regret the amount they have spent on clothing $(41.9 \%)$ but would rarely let others be aware that their expensive $(41.9 \%)$ or fashionable (39.5\%) clothing was bought at a discount.

Table 4 - Frequencies and Kruskal-Wallis for Shopping Behaviour

\begin{tabular}{|c|c|c|c|c|}
\hline & \multicolumn{3}{|c|}{$\%$} & \multirow{2}{*}{$\begin{array}{l}\text { Kruskal- } \\
\text { Wallis* } \\
\text { (p-value) }\end{array}$} \\
\hline & $\begin{array}{l}\text { Low } \\
\text { CC }\end{array}$ & $\begin{array}{l}\text { Medium } \\
\text { CC }\end{array}$ & $\begin{array}{c}\text { High } \\
\text { CC }\end{array}$ & \\
\hline How often do you purchase a new item of expensive clothing? & $\mathbf{m h}$ & lh & $\operatorname{lm}$ & $<0.001$ \\
\hline Weekly & 1.1 & 1.2 & 26.7 & \\
\hline Monthly & 12.4 & 37.2 & 38.4 & \\
\hline Every 6 months & 41.6 & 50.0 & 29.1 & \\
\hline Once a year & 28.1 & 10.5 & 5.8 & \\
\hline Never & 16.9 & 1.2 & 0 & \\
\hline How often do you purchase a new item of fashionable clothing? & mh & lh & $\operatorname{lm}$ & $<0.001$ \\
\hline Weekly & 4.5 & 9.3 & 43.0 & \\
\hline Monthly & 29.2 & 75.6 & 48.8 & \\
\hline Every 6 months & 28.1 & 15.1 & 7.0 & \\
\hline Once a year & 18.0 & 0 & 0.0 & \\
\hline Never & 20.2 & 0 & 1.2 & \\
\hline $\begin{array}{l}\text { On average, how much would you usually spend per month on } \\
\text { clothing? }\end{array}$ & $\mathbf{m h}$ & lh & $\operatorname{lm}$ & $<0.001$ \\
\hline Less than $£ 50$ & 38.2 & 12.8 & 1.2 & \\
\hline$£ 51-£ 100$ & 31.5 & 21.3 & 8.1 & \\
\hline$£ 101-£ 200$ & 21.3 & 28.9 & 25.6 & \\
\hline$£ 201-£ 300$ & 3.4 & 27.7 & 18.6 & \\
\hline$£ 301-£ 500$ & 1.1 & 5.8 & 20.9 & \\
\hline$£ 401-£ 500$ & 4.5 & 2.3 & 15.1 & \\
\hline$£ 501+$ & 0 & 1.2 & 10.5 & \\
\hline How often have you gone into debt to purchase clothing? & mh & $\mathbf{I}$ & l & $<0.001$ \\
\hline Never & 84.3 & 37.2 & 36.0 & \\
\hline Rarely & 11.2 & 26.7 & 30.2 & \\
\hline Sometimes & 3.4 & 22.1 & 23.3 & \\
\hline Often & 1.1 & 12.8 & 10.5 & \\
\hline Always & 0 & 1.2 & 0 & \\
\hline $\begin{array}{l}\text { How often do you regret the amount you have spent on } \\
\text { clothing? }\end{array}$ & $\mathbf{m h}$ & 1 & $\mathbf{l}$ & $<0.001$ \\
\hline Never & 49.4 & 19.8 & 16.3 & \\
\hline Rarely & 31.5 & 32.6 & 18.6 & \\
\hline Sometimes & 19.1 & 32.6 & 41.9 & \\
\hline Often & 0 & 14.0 & 18.6 & \\
\hline Always & 0 & 1.2 & 4.7 & \\
\hline $\begin{array}{l}\text { Would you let others be aware if an item of expensive clothing } \\
\text { was purchased at a discount? }\end{array}$ & mh & lh & $\operatorname{lm}$ & $<0.001$ \\
\hline Never & 1.1 & 12.8 & 27.9 & \\
\hline Rarely & 6.7 & 18.6 & 41.9 & \\
\hline Sometimes & 25.8 & 27.9 & 20.9 & \\
\hline Often & 33.7 & 36.0 & 9.3 & \\
\hline Always & 32.6 & 4.7 & 0 & \\
\hline $\begin{array}{l}\text { Would you let others be aware if an item of fashionable } \\
\text { clothing was purchased at a discount? }\end{array}$ & $\mathbf{m h}$ & lh & $\operatorname{lm}$ & $<0.001$ \\
\hline Never & 0 & 10.5 & 19.8 & \\
\hline Rarely & 5.6 & 14.0 & 39.5 & \\
\hline Sometimes & 28.1 & 25.6 & 24.4 & \\
\hline Often & 24.7 & 41.9 & 14.0 & \\
\hline Always & 41.6 & 8.1 & 2.3 & \\
\hline
\end{tabular}




\section{CONCLUSIONS}

As intended, the results provided a clearer insight into conspicuous consumption in the context of clothing and its relationship with public self-consciousness, materialism and self-esteem as they relate to the expensive and fashionable dimensions. In addition, the nature of the relationship between conspicuous consumption and the important variables of demographics and shopping behaviour was also uncovered. Taken together, the results will be of particular interest and value to retail marketers when designing strategies to promote their products.

Materialism and domain-specific self-esteem results showed a much greater relationship between expensive clothing and conspicuous consumption than for fashionable clothing. However, the public self-conscious mean results showed individuals prefer fashionable to expensive clothing. This may be due to conspicuous fashion becoming more prevalent and accessible to the masses (Varman and Vikas 2005) helping those with less money but better taste to compete with the wealthier set (Chaudhuri and Majumdar 2006). With many more people opting to show conspicuousness through purchasing in-vogue clothing, the latest fashions are clearly seen as status revealing (Scott 2010). This explains why the ranked correlations alternate between expensive and fashionable clothing, with both being as important as one another for public self-conscious individuals.

Second, all three concepts showed that when discussing success and wealth signalled by clothing, all the expensive variable correlations with conspicuous consumption were higher than their fashion equivalents. As with previous studies, most conspicuous consumption definitions include purchasing items to signal wealth and status (Chen et al. 2008; Bearden and Etzel 1982; Veblen 1934) to indicate success in life. Therefore, it could be deduced that for higher conspicuous young professionals expensive clothing still dominates fashionable clothing as the easiest way to portray wealth and success. 
Third, public self-consciousness, materialism and domain-specific self-esteem either show no difference between medium and high conspicuous individuals regarding fashionable clothing or at least a much smaller difference when compared with expensive clothing. This difference could be due to the bandwagon (Duesenberry 1949) and snob (Mason 1981) effects. The snob effect shows that individuals will fight to be exclusive (Page 1992) and therefore will continue to purchase expensive clothing in order to stand out from the conspicuous masses who follow the bandwagon effect. Additionally, overall there is far less mean difference between medium and high conspicuous consumers than there is between low and medium. This indicates that those with low conspicuousness will require a noticeably different marketing approach than for medium and high.

With regards to demographics, no difference emerged between medium and high individuals, although there was a difference between low and the higher levels. While this agrees partly with Heffetz (2011) who states overall demographics is unrelated to conspicuous consumption, it appears that the relationship is not a linear one. Contradictory to Sundie et al. (2011), who state men were more conspicuous than women, this research found no significant difference across gender. This study found that low conspicuous individuals are more likely to be within the older age band, married with children and paying a home mortgage while medium and high conspicuous individuals fall within the middle age band, are more likely to be single or in a stable relationship, childless and living in rented accommodation.

Fifth, with two exceptions, shopping behaviour varied across conspicuous consumption groups. While medium and high conspicuous individuals were both likely to purchase fashionable clothing, highly conspicuous individuals purchased expensive clothing more frequently. Low conspicuous individuals spend the least on their clothing, while the medium and high conspicuous individuals spend moderately and highest respectively. They are less likely to go into debt than high conspicuous individuals, mirroring Scott and Lewis' (2001) 
results, and less likely to regret their purchase decisions than high conspicuous individuals as found by Clarke and Mortimer (2013). They are also more likely to inform others if the clothing was a sale item, while medium conspicuous individuals will be less likely and those with high conspicuousness highly unlikely to share this information. Clearly, this is an indication that marketers for high end retail stores should be targeting the most conspicuous individuals in order to maximise their sales figures.

Finally, the research has indicated that expensive and fashionable clothing are both used conspicuously to gain status and social belonging which agrees with previous research (Nelissen and Marijn 2011). It is clearly shown within this research that expensive clothing purchases are the more conspicuous of the two. Social status and belonging have a relationship with conspicuous consumption in the context of clothing and therefore each can affect a consumer's shopping habits. Therefore, if consumers believe opinions of others matter or purchasing products will portray status or boost self-esteem they will become much more conspicuous.

\subsection{Implications for practice}

The results of this study have several implications for fashion retailers. Low conspicuous individuals had lower levels of public self-consciousness, materialism and self-esteem in the context of clothing and more financial commitments, and therefore marketers need to emphasise value for money and utilitarian benefits of clothing, rather than any social and status advantages. Furthermore, motivating this segment to purchase conspicuous clothing by highlighting the fashionability attribute will be more effective than using expensiveness. This said, the majority of this segment still purchases expensive clothing (albeit not very frequently) perhaps for a special occasion, and marketers of conspicuous clothing could also capitalise on 
this infrequent purchase. They do not have issues with others knowing they make discounted purchases so sale advertising can be much more direct and obvious.

High conspicuous individuals are clearly attracted towards expensive goods with $38.4 \%$ making an expensive clothing purchase each month. This makes them an obvious target for luxury clothing advertising which should emphasise the effect expensive clothing have on an individual's image, social respect and self-esteem. They are more likely to buy expensive goods yet they are less likely to disclose that they bought it at discount. When shops have sales they should be more subtle (e.g. no big sale signs) as the consumer still wants to feel they are purchasing expensive goods. As price is an important signal to affect the person's materialism, self-esteem and public self-consciousness, price reductions need to be moderate so as to continue to provide these benefits. High-end marketers need to ensure that their advertisements imply a sense of attachment to higher status groups with the clothing portraying images of wealth, success and exclusivity. This style of advertisement is ideally suited for celebrity endorsements as they present images of an aspired lifestyle.

More than half of the medium conspicuous group will purchase fashionable clothing each month spending $£ 101-£ 300$ and should be noted as a substantial market by the retail clothing industry. The fact that medium conspicuous individuals' profile is closer to the high conspicuous than the low conspicuous group suggests that much of the approach advocated for the high conspicuous individuals could work with them, pending minor adjustments. Instead of a re-occurring activity, medium conspicuous individuals may be sensitive to advertisement appeals that portray expensive clothing as aspirational in the context of a social occasion (e.g. attending an event) or as a 'treat' rewarding hard work or an personal achievement. 


\subsection{Limitations and further research}

The study used convenience and snowball sampling and was mainly restricted to individuals working in the London (UK) area, therefore samples may not be fully representative of the wide UK population. While the sample size was seen as fair to a number of studies (Stoker 1989; Lazerwitz 1968) a larger sample could give an even more accurate description of the patterns studies in this paper. As the research is only studying young professionals, it may be difficult for marketers to generalise the results to all ages and professions, especially because this research showed that smaller age groups can differ in their conspicuous consumption. Another limitation is that the findings only focus on expensive and fashionable clothing and therefore cannot be generalised to all types of clothing.

This research was targeted at young professionals therefore an option would be to explore nonprofessionals or target a larger population to explore the difference in behaviour among different sections of society. As there was shown to be a divide between expensive and fashionable clothing it would be of interest for future research to further investigate which type of clothing that has the largest influence on conspicuous consumption. This research was beneficial as it looked at a specific product, clothing, which gave a greater insight to the variables and conspicuous consumption. It would be interesting to carry out research using other conspicuous products to see if there was any variations in the findings. As the British tourist trade is booming with many foreign visitors constantly arriving in the country, such as the affluent Chinese who spent close to $£ 1$ billion on high-end good during the 2010 January sales (Mintel 2010), there are definite benefits and opportunities for research into the purchase decision process and spending behaviour of foreign visitors to the UK. 


\section{REFERENCES}

Amaldoss, W. and Jain, S. (2005), “Conspicuous Consumption and Sophisticated Thinking”, Management Science, 51(10), 1449-1466.

Banister, E.N. and Hogg, M.K. (2004), 'Negative symbolic consumption and consumers' drive for self-esteem: The case of the fashion industry", European Journal of Marketing, 38 (7), 850-868.

Bearden, W.O. and Etzel, M.J. (1982), "Reference Group Influence on Product and Brand Purchase Decisions", Journal of Consumer Research, 15 (9), 473-481.

Belk, R.W. (1988), “Possessions and the extended self”, Journal of Consumer Research, 15 (2), 139-168.

Belk. R.W. (1985), "Materialism: Traits aspects of living in the material world", Journal of Consumer Research, 12 (3), 265-280.

Burnkrant, R.E. and Page, T.J. (1981), “On the management of self-images in social situations: the role of public self-consciousness”, In: Mitchell, A., Association for Consumer Research. Advances in Consumer Research, 9 , 452-455.

Bushman, B.J. (1993), "What's in a name? The moderating role of public self-consciousness on the relation between brand label and brand preference", Journal of Applied Psychology, 78 (5), 857-861.

Carpenter, J.M., Moore, M. and Fairhurst, A.E. (2005), “Consumer shopping value for retail brands", Journal of Fashion Marketing and Management, 9 (1), 43-53.

Chaudhuri, H. and Majumdar, S. (2006), "Of diamonds and desires: Understanding conspicuous consumption from a contemporary marketing perspective”, Academy of Marketing Science Review, 10 (8), 1-18.

Chen, E.Y., Yeh, N. and Wang, C.P. (2008), "Conspicuous consumption: A preliminary report of scale development and validation", Advances in Consumer Research, 35 (1), 686.

Clarke, P.D. and Mortimer, G. (2013), "Self-gifting guilt: an examination of self-gifting motivations and postpurchase regret", Journal of Consumer Marketing, 30 (6), 472-483.

Cohen, J. (1988), Statistical Power Analysis for the Behavioral Sciences. 2nd edition. New Jersey: Lawrence Erlbaum Associates.

Corneo, G. and Jeanne, O. (1997), “Conspicuous Consumption, Snobbism and Conformism”, Journal of Public Economics, 66 (1), 55-71.

De Fraja, G. (2008), "Sexual Selection and Conspicuous Consumption”, Journal of Economic Behavior and Organization, 72 (1), 51-69.

Dittmar, H. (2005), “A New Look at 'Compulsive Buying': Self-discrepancies and Materialistic Values as Predictors of Compulsive Buying Tendency”, Journal of Social and Clinical Psychology, 24 (6), 832-859.

Doherty, K. and Schlenker, B. R. (1991), "Self-Consciousness and Strategic Self-Presentation”, Journal of Personality, 59 (1), 1-18.

Duesenberry, J. (1949), Income, savings and the theory of consumer behaviour. Cambridge: Harvard University Press.

Dunn, O.J. (1964), “Multiple comparisons using rank sums”, Technometrics, 6 (3), 241-252.

Fenigstein, A. (1979), "Self-consciousness, self-attention, and social interaction", Journal of Personality and Social Psychology, 37 (1), 75-86. 
Ghosh, A. and Varshney, S. (2013), "Luxury Goods Consumption: A Conceptual Framework", South Asian Journal of Management, 20 (2), 146.

Gil L.A, Kwon K.N., Good L.K. and Johnson L.W. (2012), "Impact of self on attitudes toward luxury brands among teens", Journal of Business Research, 65 (10), 1425-1433.

Gould, S.J. and Barak, B. (2001), "Public self-consciousness and consumer behaviour", The Journal of Social Psychology, 128 (3), 393-400.

Gray, C.D. and Kinnear, P.R. (2012), IBM SPSS Statistics 19 Made Simple. Hove and New York: Psychology Press.

Grubb, E.L. and Grathwohl, H.L. (1967), “Consumer self-concept, symbolism and market behavior: a theoretical approach”, Journal of Marketing, 31 (41), 22-27.

Heffetz, O. (2011), “A Test of Conspicuous Consumption: Visibility and Income Elasticities”, The Review of Economics and Statistics, 93 (4), 1101-1117.

Hirsch, F. (1976), Social limitation to growth, Cambridge: Harvard University Press.

James, W. (1890). The Principles of Psychology. New York: Dover.

Kapferer, J. N. and Michaut, A. (2015), "Luxury and sustainability: a common future? The match depends on how consumers define luxury", Luxury Research Journal, 1 (1), 3-17.

Kastanakis, M. N. and Balabanis, G. (2014). "Explaining variation in conspicuous luxury consumption: An individual differences' perspective", Journal of Business Research, 67 (10), 2147-2154.

Lazerwitz, B. (1968). "Sampling Theory and Procedures". In: Blalock Jr, H.M. and Blalock, A.B., eds. Methodology in Social Research. New York: McGraw-Hill, 278-328.

Marsh, H.W., Craven, R.G. and Martin, A. (2006), "What is the nature of self-esteem: Unidimensional and multidimensional perspectives". In: M. Kernis., Ed. Self-esteem: Issues and Answers [online]. Hove: Psychology Press, 16-24.

Mason, R. (1981), Conspicuous Consumption: A Study of Exceptional Consumer Behavior. England: Gower.

Memushi, A. (2013), "Conspicuous Consumption of Luxury Goods: Literature Review of Theoretical and Empirical Evidences”, International Journal of Scientific and Engineering Research, 4 (12), 250-255.

Mintel (2010). The Chinese are the biggest spenders on luxury items in Britain [online]. London: Mintel Group.

Mintel (2012). Consumer spending outpaces income gains [online]. London: Mintel Group.

Mintel (2013). British Lifestyles 2013: Examining the Legacy of the Economic Downturn [online]. London: Mintel Group.

Moschis, G.P. (1981), "Patterns of consumer learning”, Journal of the Academy of Marketing Science, 9 (2), 110 26.

Nelissen, R. and Marijn H. (2011), "Social Benefits of Luxury Brands as Costly Signals of Wealth and Status", Evolution and Human Behavior, 32 (5), 343-355.

O`Cass, A. and Muller, T.E. (1999), “A study of Australian materialistic values, product involvement and selfimage/product-image congruency relationships for fashion clothing”, Academy of Marketing Science, 3 (4), 113 125.

O’Shaughnessy, J. and O’Shaughnessy, N.J. (2002), “Marketing, the consumer society and hedonism”, European Journal of Marketing, 36 (5), 524-547. 
O'Cass, A. and McEwen, H. (2004), "Exploring Consumer Status and Conspicuous Consumption", Journal of Consumer Behaviour, 4 (1), 25-39.

Page, C. (1992), “A History of Conspicuous Consumption”, In: Rudmin, F. and Richins, M., eds. Workshop on Materialism and Other Consumption Orientations Conference Proceedings. UT: Association of Consumer Research, 82-87.

Phau, I. and Cheong, E. (2009), "Young consumers' evaluations of diffusion brands", Young Consumers: Insight and Ideas for Responsible Marketers, 10 (3), 210-224.

Podoshen, J.S. and Andrzejewski, S.A. (2012), “An Investigation into the Relationships Between Materialism, Conspicuous Consumption, Brand Loyalty and Impulse Buying”, Journal of Marketing Theory and Practice, 20 (3), 319-334.

Podoshen, J. S., Li, L., and Zhang, J. (2011), "Materialism and conspicuous consumption in China: A crosscultural examination", International Journal of Consumer Studies, 35(1), 17-25.

Pyone, J.S. and Isen, A.M. (2011), "Positive affect, intertemporal choice, and levels of thinking: Increasing consumers' willing ness to wait”, Journal of Marketing Research, 48 (3), 532-543.

Rahman, O., Jiang, Y., and Liu, W. S. (2010), "Evaluative criteria of denim jeans: A cross-national study of functional and aesthetic aspects", The Design Journal,13(3), 291-311.

Richins, M.L. and Dawson, S. (1992), “A Consumer Values Orientation for Materialism and Its Measurement: Scale Development and Validation”, Journal of Consumer Research, 19 (3), 303-16.

Richins, M.L. (1994), "Special possessions and the expression of material values", Journal of Consumer Research, 21 (3), 522-533.

Rosenberg, M. (1965), Society and the adolescent self-image. Princeton, NJ: Princeton University Press.

Rosenberg, M., Schooler, C., Schoenbach, C. and Rosenberg, F. (1995), "Global self-esteem and specific selfesteem: Different concepts, different outcomes”, American Sociological Review, 60 (1), 141-156.

Rubin, K.H. (1998), "Social and emotional development from a cross-cultural perspective, Developmental Psychology, 34 (4), 611-615.

Scott, A. and Lewis, A. (2001), "Student loans: The development of a new dependency culture?", In: Scott, A., Lewis, A. and Lee, S., Eds. Student debt: The causes and consequences of undergraduate borrowing in the UK. Bristol: The Policy Press, 49-58.

Scott, D. (2010), “What would Veblen say?”, Leisure Sciences, 32 (3), 288-294.

Sirgy, J. (1982), "Self-Concept in Consumer Behavior: A Critical Review", Journal of Consumer Research, 9 (3), 287-300.

Sivanathan, N. and Pettit, N.C. (2010), "Protecting the self through consumption: Status goods as affirmational commodities", Journal of Experimental Social Psychology, 46 (3), 564-57

Spero, I. and Stone, M. (2004), "Agents of change: how young consumers are changing the world of marketing", Qualitative Market Research: An International Journal, 7 (2), 153-159.

Stoker, T.M., (1989), “Tests of addictive derivative constraints”, Review of Economic Studies, 56 (4), 535-552.

Sundie J.M., Kenrick, D.T., Grikevicius, V., Tybur, J.M., Vohs, K.D. and Beal, D.J. (2011), "Peacocks, Porsches, and Thorstein Veblen: Conspicuous Consumption as a Sexual Signalling System", Journal of Personality and Social Psychology, 100 (4), 664-680.

Tatzel, M. (2002), "Money worlds and well-being: An integration of money dispositions, materialism and pricerelated behaviour", Journal of Economic Psychology, 23 (1), 103-126. 
Tepper-Tian, K., Bearden, W. and Hunter, G. (2001), “Consumers' Need for Uniqueness: Scale Development and Validation", Journal of Consumer Research, 28 (1), 50-66.

Tolbert, S. L., Kohli, C. and Suri, R. (2014), "Who pays the price for loyalty? The role of self-consciousness", Journal of Product \& Brand Management, 23 (4/5), 362-371.

Trigg, A. (2001), "Veblen, Bourdieu, and Conspicuous Consumption”, Journal of Economic Issues, 35 (1), 99 115.

Truong, Y. and McColl, R. (2011), "Intrinsic motivations, self-esteem, and luxury goods consumption”, Journal of Retailing and Consumer Services, 18 (6), 555-561.

Truong, Y. (2010), "Personal Aspirations and the Consumption of Luxury Goods", International Journal of Market Research, 52 (5), 653-671.

Truong, Y., Simmons, G., McColl, R. and Kitchen, P.J. (2008), "Status and Conspicuousness - Are They Related? Strategic Marketing Implications for Luxury Brands”, Journal of Strategic Marketing, 16 (3), $189-203$.

Tunnel, G. (1984), "The discrepancy between private and public selves: Public self-consciousness and its correlates", Journal of Personality Assessment, 48 (5), 549-555.

Varman, R, and Vikas, R.M. (2005), Media, rising consumer culture and the working class, Proceedings of the Critical Management Studies [online], 42.

Veblen, T.B. (1934), The Theory of the Leisure Class [online]. New York: The Modern Library.

Vigneron, F. and Johnson, L.W. (2004), "Measuring perceptions of brand luxury", Journal of Brand Management, 11 (6), 484-506.

Wadman, W.M. (2000), Variable quality in consumer theory: toward a dynamic microeconomic theory of the consumer, New York: M.E Sharpe, Inc.

Walpole (2013), UK Luxury Benchmark Survey [online]. London: Walpole British Luxury.

Weinberg, S.L. and Abramowitz, S.K. (2002), Data Analysis for the Behavioural Sciences Using SPSS. Cambridge: Cambridge University Press.

Wiedmann, K., Hennigs, N. and Siebels, A. (2007), "Measuring consumers' luxury value perception: A crosscultural framework", Academy of Marketing Science Review, 11 (7), 1-23.

Winkelmann, R. (2012). “Conspicuous consumption and happiness”. Journal of Economic Psychology, 33 (1), 183-191.

Wong, N.Y. (1997), "Suppose you own the world and no one knows? Conspicuous Consumption, Materialism and Self", Advances in Consumer Research [online], 24 (1), 197-203.

Woodside, A. G. (2012). “Economic psychology and fashion marketing theory appraising veblen's theory of conspicuous consumption”. Journal of Global Fashion Marketing, 3 (2), 55-60.

$\mathrm{Xu}, \mathrm{Y}$. (2008), “The influence of public self-consciousness and materialism on young consumers' compulsive buying", Young Consumers, 9 (1), 37-48. 